\title{
ADAPTIVE LIGHTING SYSTEM MODELLING AND ANALYSIS
}

\author{
SULIEMAN Q. ABU-EIN \\ Department of Mechanical Engineering, Faculty of Engineering Technology,
}

Al-Balqa Applied University, Amman, Jordan

\begin{abstract}
Modelling and analysis for the adaptive lighting system for automobiles will be presented in this work, the system helps drivers to reveal unseen or hidden objects on streets during night driving, all factors affect the efficiency and performance of adaptive lighting system streets will be studied. It is found that the angle of rotation of the front lights on adaptive lighting systems depends on many parameters like: the speed of the car and the yaw rate. Also it is found that as the velocity increases the angle variation increases and as the yaw rate of the tires increases during turning the angle increases.
\end{abstract}

KEYWORDS: Adaptive, Lighting System, Modelling and Analysis \& Night Driving

Received: Apr 01, 2019; Accepted: Apr 21, 2019; Published: Jun 08, 2019; Paper Id.: IJMPERDJUN2019156

\section{LIST OF ABBREVIATIONS}

I Transmission ratio

H Efficiency

Te Denotes Torque of Engine

A Throttle Input

LED Light Emitting Didoes

IC Integrated Circuit

AHL Adaptive Head Light

PB Passing Beam

AHS Frontal adjustment system

AFLS Adaptive Front Lighting System

\section{INTRODUCTION}

Safety on roads during driving vehicles becomes recently one of the highest priorities for the designers and developers of cars. Passive and active safety systems are originally developed to enable vehicles to accomplish high safety levels and to guarantee comfortable driving conditions. Most of cars' designers and researchers tried their best efforts to develop systems with preventive and active capabilities, so as to actively achieve a safe driving using the state of the art mechatronics systems. The objectives of development in active safety systems in general was to eliminate reaction-time of the relation of driver-vehicle and to enhance the safety of roads and the comfort of driving. As it contributes on almost $90 \%$ of the needed information to drivers. It was stated in [1] that driving automobiles is mainly a visual work. 
Under bad weather conditions, drivers face difficulty in seeing traffic controllers, walkways, moreover, it is difficult to see other automobiles, walkers, and animals (such as camels). Research showed that visual capabilities drop from $90 \%$ to less than $4 \%$ during rainy or foggy nights. Moreover, in Germany, it was found that more than $40 \%$ of car accidents leading to death that occurred at night-time, in spite of the $80 \%$ drop of traffics on roads compared to day [3]. Researchers in [4] concluded that better solutions can be achieved using better lighting technologies, better power electronics, mechanics \& motors, sensors, and other control and design facilities.

Statistics in 2004 showed that out of 494,851 accidents in Turkey, the number of died people was 3,082, the number of injured people was 109,681 and the losses were about $\$ 0.5$ billion. In 2002, statistics showed that a 1,023 incidents costs 153 billion dollars and the number of died people was 1,685 [2].

Lighting facilities had been improved significantly in current automobiles. Modern technologies in such field provided new lighting sources that are powerful, these technologies include sensors and many other dynamic lighting facilities and systems. Frontal Headlights Adjustment System (FHAS) is an advancement in lighting systems for the new generation that is beneficial for both drivers and road users.

In [6] devices in a loop simulation of the frontal adjustment system for cars and Adaptive Headlight (AHL) as an active safety system were demonstrated. AHLs insures better night vision by rotating left and right low beam to maintain the parallelism of light beam with the road's curves as much as possible, their proposed real-time models are displayed for vehicles and roads used first and the internal loop simulation is then presented to test the adaptive lamp concept, finally, a real-time simulation is implemented to demonstrate their approach [6].

An urban smart lighting system capable to autonomously control the street lamp lighting level by exploiting data related to vehicles (bus, car, motorcycle and bike) and/or pedestrian's traffic in a specific area was presented in [11]. The system was able to set the lighting level on the basis of required needs and allows one to reduce energy costs.

A suggestion of a model to improve visibility for driver and so achieve a significant increase in safety and driving comfort in [12]. They suggested to use a flexible front light for automobiles to illuminate road ahead in the night at corner. Adaptive front lighting system (AFS) helps improve driver's visibility at night time hence achieving enhance safety. AFS (adaptive front-lighting system) used to detect information about corner in advance with help of sensor which detect the information send it to motor to adjust headlamps to get the lighting beam which was suitable for the corner. Through this way, it could avoid "blind spot" caused by the fixed lighting area when coming into the corner, and improve driving safety [12]. In [13] there was a suggestion for new architecture of the AFS. This architecture is powerful and intelligent using the PWM technique on ARDUINO Board replaces the old mechanical system based on stepper motors.

\section{AIM AND OBJECTIVES}

- Constructing and analyzing adaptive lighting system for automobiles.

- Studying the factors affect the performance of the adaptive lighting system.

\section{ADAPTIVE LIGHTING SYSTEM}

Driving at night or twilight partake a major cause of automotive accidents. Even though the average distance driven during the nighttime is $75 \%$ as lesser as compared to the average distance driven during the daytime, the amount of road accidents with fatalities or injuries in the sun down are $300 \%$ more than as compared with the day time. Again, the 
statistical studies from the National safety council disclose the fact that 55\% of all road accidents in night or twilight are occurring in the curved roads due to insufficient illumination and poor judgment of curves. A 50 year old driver needs 3 times the illumination needed for a driver of 20 year old. Table 1 shows a single-car fatal and non-fatal crash counts by driver age, gender, and time of day in Great Britain, 2002-2012 [14]. It is clear form Table 1 that number of night accidents in some age range increasing and greater than that of day accidents which proves that there is a problem at night related to the ability of drivers to get clear vision.

Table 1 single-car fatal and non-fatal crash counts by driver age, gender, and time of day in Great Britain, 20022012. [14]

Table 1

\begin{tabular}{|c|c|c|c|c|c|c|}
\hline & \multicolumn{3}{|c|}{ Fatal crash counts } & \multicolumn{3}{|c|}{ Nonfatal crash counts } \\
\hline & Day & Evering & Night & Day & Evening & Night \\
\hline \multicolumn{7}{|l|}{ Males } \\
\hline $17-20$ & 16 & 10 & 44 & 2,081 & 938 & 2,251 \\
\hline $21-29$ & 35 & 16 & 66 & 4,101 & 1,347 & 2,616 \\
\hline $30-39$ & 40 & 16 & 35 & 4.702 & 1.218 & 1.637 \\
\hline $40-49$ & 28 & 10 & 19 & 4,251 & 948 & 1,112 \\
\hline $50-59$ & 17 & 7 & 12 & 3,086 & 591 & 578 \\
\hline $60-69$ & 12 & 2 & 5 & 1,682 & 286 & 234 \\
\hline $70+$ & 19 & 2 & 2 & 1,188 & 155 & 101 \\
\hline \multicolumn{7}{|l|}{ Females } \\
\hline $17-20$ & 3 & 1 & 6 & 949 & 342 & 568 \\
\hline $21-29$ & 6 & 2 & 7 & 2,069 & 539 & 610 \\
\hline $30-39$ & 6 & 2 & 4 & 2,228 & 426 & 324 \\
\hline $40-49$ & 6 & 1 & 2 & 1,831 & 333 & 215 \\
\hline $50-59$ & 3 & 1 & 1 & 1.079 & 182 & 108 \\
\hline $60-59$ & 2 & 0 & 0 & 553 & 79 & 40 \\
\hline $70+$ & 6 & 0 & 0 & 474 & 50 & 22 \\
\hline
\end{tabular}

Figure 1 shows the principle of light function according to adaptive lighting system suggested, it is clear that the adaptive lighting system offers a more clear vision to both drivers and pedestrians during night than that not adaptive.
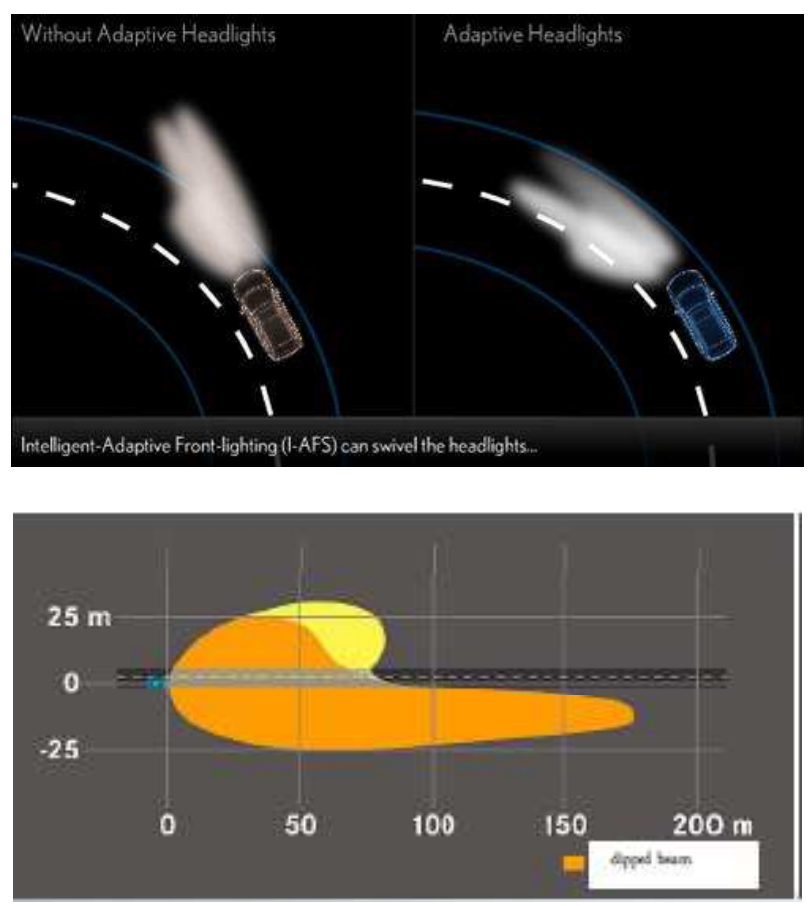

Figure 1: Principle of Light Function According to Adaptive Lighting System Suggested 
Figure 2 shows the adaptive lighting system.

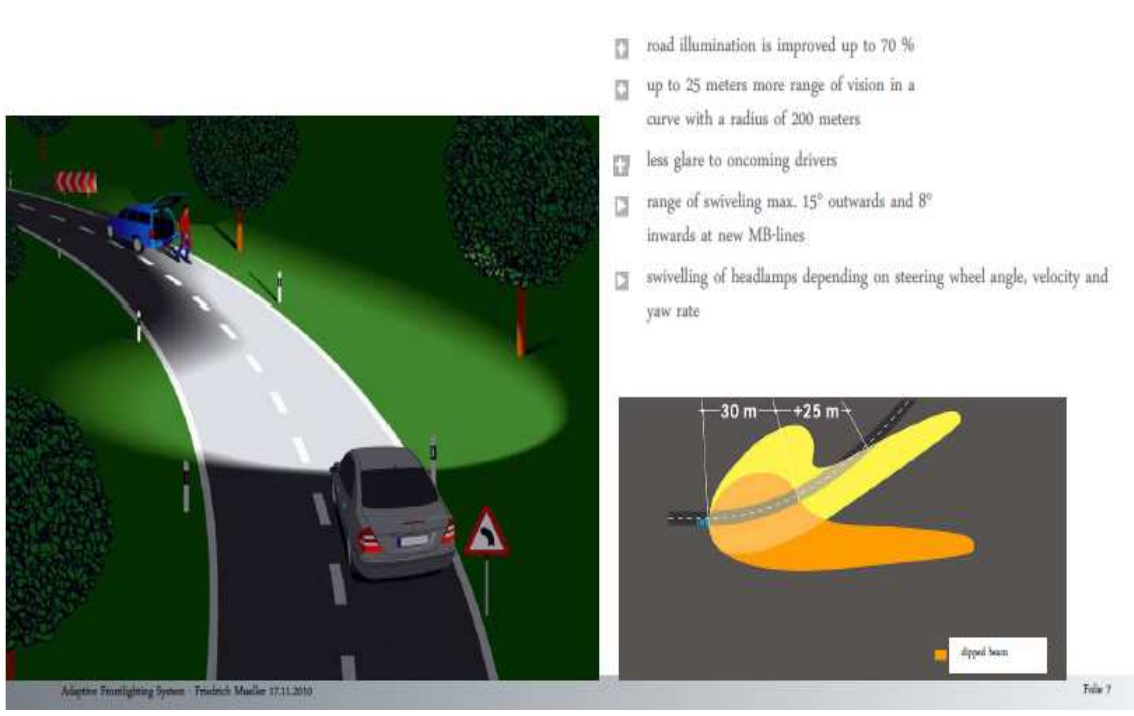

Figure 2: Adaptive Lighting System

Figure 3 shows the adaptive lighting systems for more safety at street crossing lights.
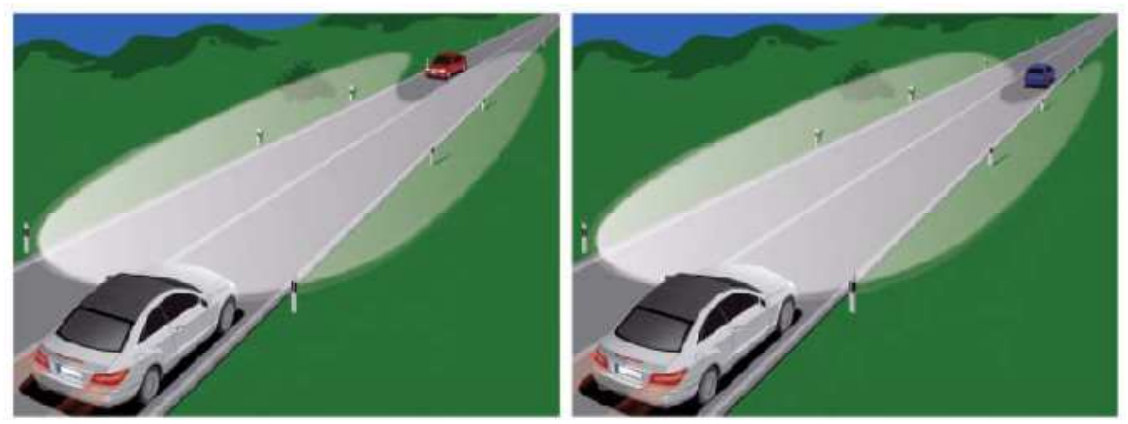

Figure 3: The Adaptive Lighting Systems for More Safety at Street Crossing Lights

\section{CONSTRUCTING AUTOMOBILE ADAPTIVE LIGHTING SYSTEM AND CONTROL}

The adaptive car lighting system does not require manual operation to turn the lamp on / off when the car is coming from the front at night. It reveals the same weather there is light in front of the next car or not. When there is light in front of the next car, it automatically turns to the ceiling light, when the car pass, it automatically turns to the head light. The sensitivity of the adaptive lighting system can be adjusted for vehicles. In this study, four LEDs were used to indicate the lamp / downlight, but for the high power lamp switch, one can connect to the Relay (Electromagnetic switch) at the 1 pin exit of IC LM358 and then it will be possible to turn on / off the light bulb High-power / downstream.

Major Functions of the AFS serve many passing beams (PB),

- Town PB.

- Basic/Country PB.

- Motorway PB.

- Wet-road PB. 
- Static and dynamic facilities for cornering and leveling lights.

\subsection{System Architecture}

Figure 4: Shows the AFS in an Automotive Network Structure

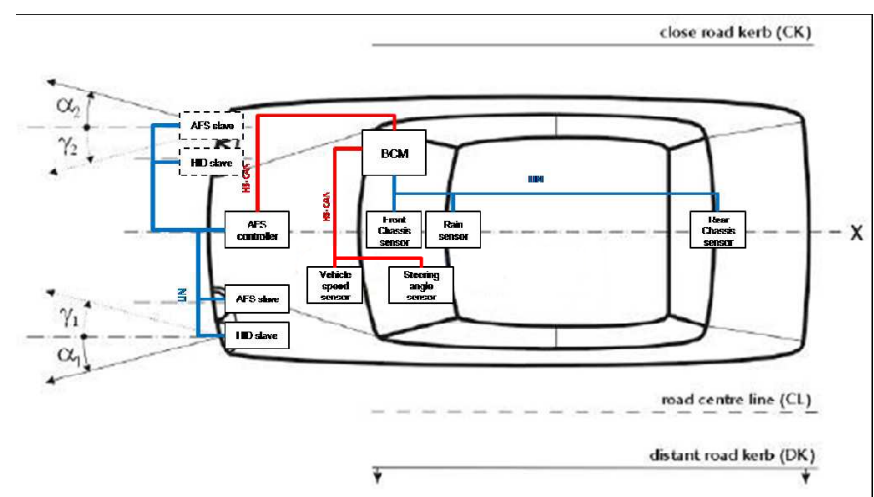

Figure 4: Automotive Network Structure

Figure 5 represents a suggestion for the simulation for the adaptive lighting system.

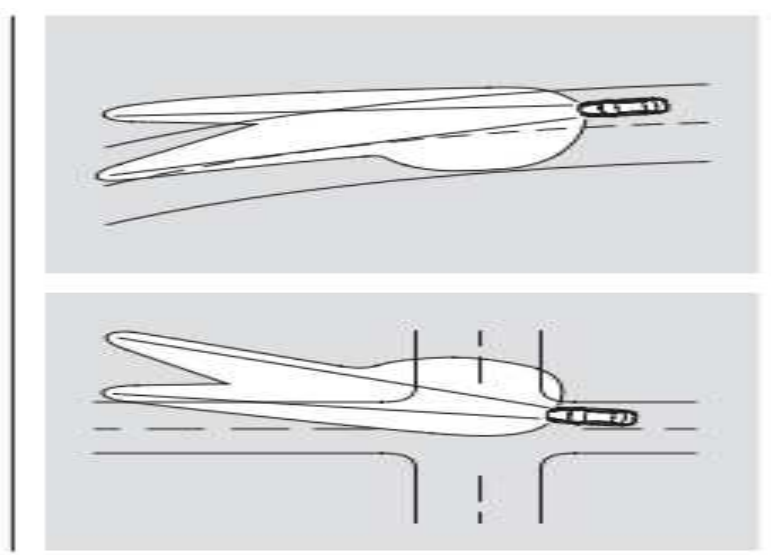

Figure 5: Adaptive Lighting System

In this work the basic single track model showed in Figure 6 will be used.

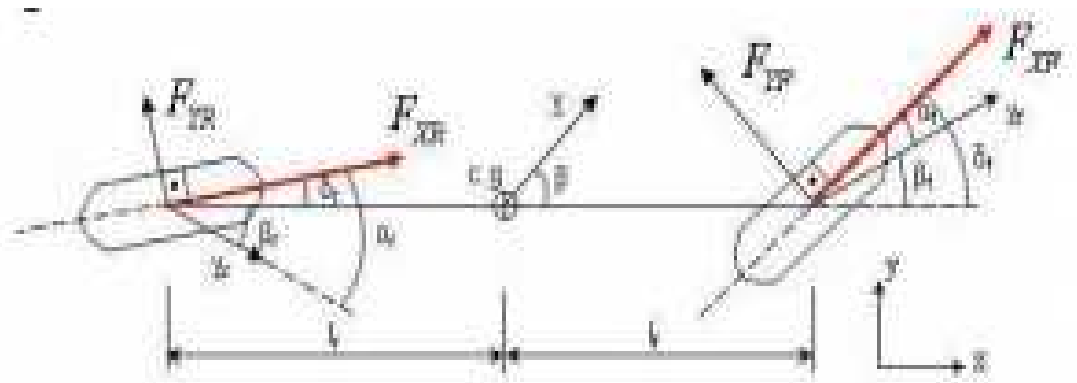

Figure 6: Single Track Model

The Adaptive Front Lighting System (AFLS) is designed to give the driver improved visibility under varying driving conditions. AFLS is able to optimize illumination in the curve roads at night, as it is dealing with numerous measures: speed, acceleration, angle of steering wheel, etc. Figure 7 shows the adaptive system compared with conventional one. 


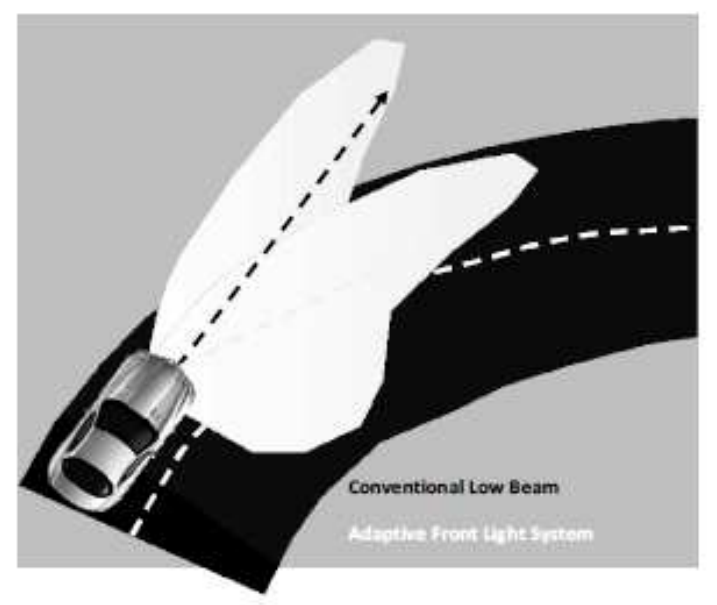

Figure 7: Adaptive and Conventional Lighting Systems

The suggested adaptive lighting system shown in Figure 3 is analyzed to investigate its properties and controlling the new system.

Tire calculations of forces is based on the usage of Dugoff tire model:

$$
\begin{aligned}
& F_{x i}=f_{i} C_{x i} \sigma_{i} \\
& F_{n}=f_{i} C_{n} \alpha_{i} \\
& f_{i}=\left\{\begin{array}{cc}
1, & F_{R i} \leq \frac{\mu_{i} F_{z i}}{2} \\
\left(2-\frac{\mu_{i} F_{\text {zi }}}{2 F_{R i}}\right) \frac{\mu_{i} F_{\text {zij }}}{2 F_{R i}}, & F_{R i}>\frac{\mu_{i} F_{\text {zi }}}{2}
\end{array}\right. \\
& F_{R i}=\sqrt{\left(C_{x i} \sigma_{i}\right)^{2}+\left(C_{n i} \alpha_{i}\right)^{2}}
\end{aligned}
$$

Where $\mathrm{i}$ equals $\mathrm{r}$ and $\mathrm{f}, \mathrm{f}$ denote front and $\mathrm{r}$ denotes rear tire sets $F$ : is the force in $\mathrm{x}, \mathrm{y}$, or $\mathrm{z}$ directions. $\mu$ : is the friction coefficients. $\bullet C_{s}$ : longitudinal stiffness of the tire. $\sigma x$ theoretical longitudinal slip, $\sigma y$ : theoretical sideslip angle The steering projection is used to characterize the expanded nonlinear single track model:

$$
\begin{aligned}
& {\left[\begin{array}{c}
\sum F_{x} \\
\sum F_{Y} \\
\sum_{Y} M_{z}
\end{array}\right]=\left[\begin{array}{cc}
-\sin \delta_{f} & -\sin \delta_{r} \\
\cos \delta_{f} & \cos \delta_{r} \\
l_{f} \cos \delta_{f} & -l_{r} \cos \delta_{r}
\end{array}\right]\left[\begin{array}{l}
F_{I F} \\
F_{I Z}
\end{array}\right]} \\
& +\left[\begin{array}{cc}
\cos \delta_{f} & \cos \delta_{r} \\
\sin \delta_{f} & \sin \delta_{r} \\
-l_{f} \sin \delta_{f} & -l_{r} \sin \delta_{r}
\end{array}\right]\left[\begin{array}{l}
F_{y z} \\
F_{x R}
\end{array}\right]
\end{aligned}
$$

Newton-Euler equation, 


$$
\left[\begin{array}{c}
m v(\dot{\beta}+r) \\
m \dot{v} \\
J \dot{r}
\end{array}\right]=\left[\begin{array}{ccc}
-\sin \beta & \cos \beta & 0 \\
\cos \beta & \sin \beta & 0 \\
0 & 0 & 1
\end{array}\right]\left[\begin{array}{c}
F_{x} \\
F_{Y} \\
M_{z}
\end{array}\right]
$$

Equation 7 and 8 show the kinematics/geometry representations.

$$
\begin{aligned}
& \tan \beta_{f}=\tan \beta+\frac{l_{f} r}{v \cos \beta} \\
& \tan \beta_{r}=\tan \beta-\frac{l_{r} r}{v \cos \beta}
\end{aligned}
$$

And the vector representation for tier center velocities are shown in equations 9 and 10.

$$
\begin{aligned}
& \vec{v}_{r}=v \cos \beta \vec{i}+\left(v \sin \beta-r l_{r}\right) \vec{j} \\
& \vec{v}_{f}=v \cos \beta \vec{i}+\left(v \sin \beta+r l_{f}\right) \vec{j} \\
& \sigma_{f}=\left\{\begin{array}{l}
\frac{R \omega_{f}-V_{f x i}}{V_{f x i}} R \omega_{f}<V_{f x i} \text { (braking) } \\
\frac{R \omega_{f}-V_{f x i}}{R \omega_{f}} R \omega_{f} \geq V_{f x i} \text { (traction) }
\end{array}\right. \\
& \sigma_{r}=\left\{\begin{array}{l}
\frac{R \omega_{r}-V_{r x i}}{V_{r x i}} R \omega_{r}<V_{r x i} \text { (braking) } \\
\frac{R \omega_{r}-V_{r x i}}{R \omega_{r}} R \omega_{r} \geq V_{r x i} \text { (traction) }
\end{array}\right.
\end{aligned}
$$

Vrxt and Vfxi: are the projected tier velocities in equations 11 and 12, all other parameters and angles are shown in Figures 4 and 6.

$$
\begin{aligned}
& V_{r x t}=\left|\vec{v}_{r}\right| \cos \alpha_{r} \\
& V_{f t r}=\left|\vec{v}_{f}\right| \cos \alpha_{f}
\end{aligned}
$$

Equation 15 shows the front tier speed.

$$
T_{e} i \eta-F_{X R} R=J_{r} \dot{\omega}_{r}
$$

Noting that $i$ denotes transmission ratio, $\eta$ denotes efficiency, Te denotes torque of engine, $\alpha$ denotes throttle input.

The vehicle trajectory $\mathrm{X}$, and $\mathrm{Y}$ are calculated using equations 16 and 17 respectively.

$$
X=\int_{0}^{t} V \cos \left(\beta+\int_{0}^{t} \dot{\psi} d t\right) d t+X_{0}
$$




$$
\begin{aligned}
& Y=\int_{0}^{t} V \sin \left(\beta+\int_{0}^{t} \dot{\psi} d t\right) d t+Y_{0} \\
& R=\frac{1}{K}=\frac{\left(1+\dot{y}^{2}\right)^{\frac{3}{2}}}{\ddot{y}}
\end{aligned}
$$

Where $\mathrm{R}$ denotes the radius of the curvature $[8,9]$.

\section{RESULTS AND DISCUSSIONS}

The last relations are used to calculate the angles of lighting directions depending on the automobile dimensions and the velocity.

Figure 8 shows the relation between the angle of lighting direction and the velocity of the car during the curvature.

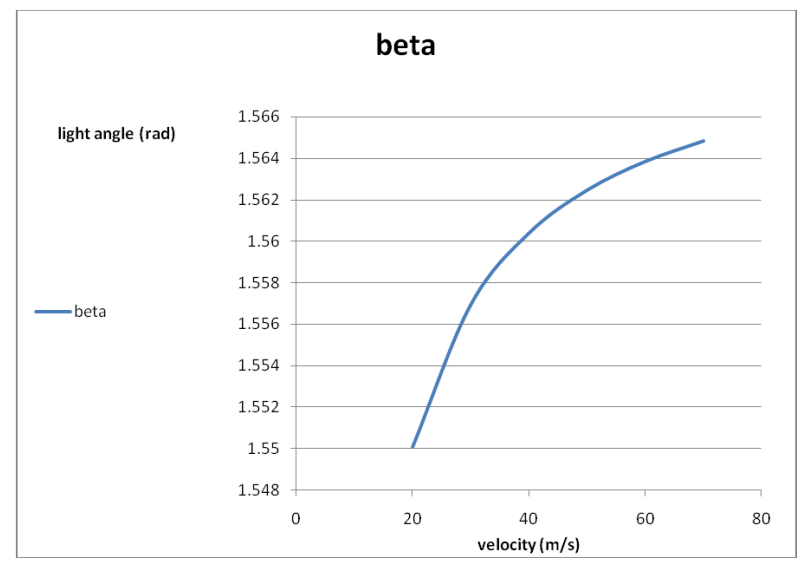

Figure 8: Front Light Angle vs. Velocity

From last figure it can be noticed that as the speed of the car increases the angle of the front light increases. For yaw rate of $0.75,1 \mathrm{f}=3 \mathrm{~m}, \beta=20$ degrees.

Figure 9 shows the relation between the angle of rotation of front lights at velocity of $50 \mathrm{~km} / \mathrm{hr}$, and yaw rate. At $1 \mathrm{f}=3 \mathrm{~m}$ and $\beta=20$.

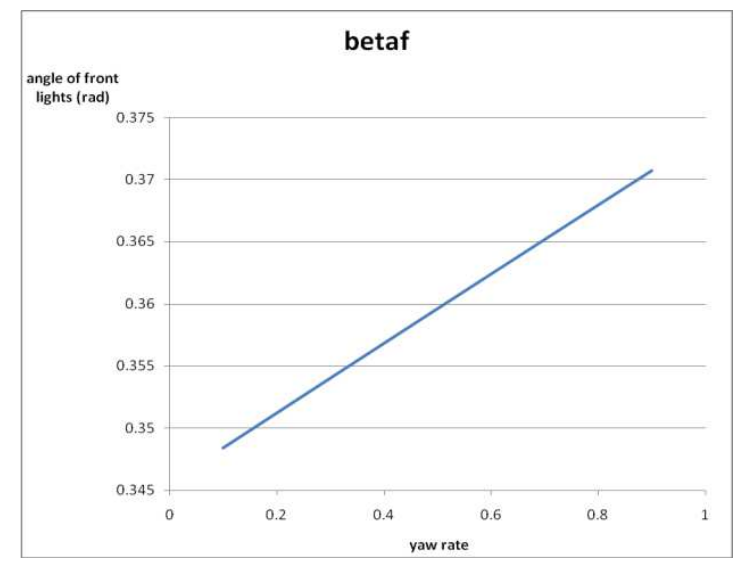

Figure 9: The Relation between Angle of Front Lights and Yaw Rate 


\section{CONCLUSIONS}

The following conclusions can be highlighted.

- The angle of rotation of the front lights on adaptive lighting systems depends on many parameters. It is found that the main two parameters are the speed of the car and the yaw rate.

- As the velocity increases the angle variation increases.

- As the yaw rate of the tires increases during turning the angle increases.

\section{ACKNOWLEDGMENT}

This work has been carried out during sabbatical leave granted to the author Sulieman Q. Abuein from Al-Balqa' Applied University (BAU) during the academic year 2016/2017. I would like to conduct my deepest appreciation to AlBalqa' Applied University (BAU) for its support and constant help during the sabbatical leave period.

\section{REFERENCES}

1. Alexander, G. J. and Lunenfeld, H. (1990), "A users' guide to positive guidance, third ed.," Report No. FHWA-SA-90-017, U.S. Department of Transportation, Federal Highway Administration, Washington, DC pp. 1-39.

2. Antony B. , Manoj M. (2014), Control Algorithm for Adaptive Front Light Systems, International Journal of Computer Trends and Technology (IJCTT) - volume 9 number 7-Mar 2014. Page 339.

3. BMWgroup:http://www.bmwworld.com/technology/lighting.htm.

4. Börnchen T., Lachmayer R., and Wallaschek J., (1999). "Methods and tools for the design of novel multi-functional automotive lighting," Proceedings of the 1999 IEEE/ASME, International Conference on Advanced Intelligent Mechatronics, Atlanta, 1999, pp. 819-825.

5. Decker D. and Schmidt C., (2005), “Adaptive Systems for Motor Vehicle Lighting First Steps and Future,” SAE World Congress, Detroit, Michigan, April 11-14, 2005, SAE Technical Paper Series No: 2005- 01-1013.

6. Hacıbekir T., Karaman S., Kural E., Öztürk E. S., Demirci M. and Güvenç B. A., 2006, Adaptive Headlight System Design Using Hardware-In-The-Loop Simulation, Proceedings of the 2006 IEEE International Conference on Control Applications, Munich, Germany, October 4-6, 2006.

7. Hamm M. and Rosenhahn E. O. (2001). "System Strategies and Technology for Improved Safety and Comfort with Adaptive Headlamps,” SAE 2001 World Congress, Detroit, Michigan March 5-8, 2001, SAE Technical Paper Series No: 2000-01-0429.

8. http://www.die.gov.tr/yillik/15_Ulastirma.pdf.

9. Neunzig D. and Lachmayer R.,(2002). “Lighting and Driver Assistances Systems for Improving Vehicle Safety,” ATZ Worldwide 6/2002, Vol. 104, pp 13-17.

10. Lexus: http://inocar.blogspot.com/2011/05/adaptive-front-lighting-system.html

11. Gagliardi G., Casavola A. , Lupia M., Cario G., Tedesco F., Scudo F., Gaccio F., and Augimeri A. (2018). A Smart City Adaptive Lighting System. 2018 Third International Conference on Fog and Mobile Edge Computing (FMEC)-IEEE

12. P. M Dubal, A. N. Shaikh (2018). Adaptive Head-Light System For Vehicle. International Journal of Engineering Research in Computer Science and Engineering. Vol. 5, Issue 2. 
13. H. Dahou1, R. El Gouri, Mohammed Alareqi, K. Mateur, A. Mezouari, A. Zemmouri, L. Hlou (2018). Design and Implementation Intelligent Adaptive Front-lighting System of Automobile using Digital Technology on Arduino board. International Journal of Electrical and Computer Engineering (IJECE) Vol. 8, No. 1.

14. Shirley Regev S., Rolison J., Salissou Moutari S. (2018). Crash risk by driver age, gender, and time of day using a new exposure methodology. Journal of Safety Research 66 (2018) 131-140 